\title{
KINETIC STUDY OF THE COBALT ELECTRODEPOSITION ONTO GLASSY CARBON ELECTRODE FROM AMMONIUM SULFATE SOLUTIONS
}

\author{
Clara Hilda Rios-Reyes \\ Departamento de Materiales, Universidad Autónoma Metropolitana-Azcapotzalco, CP 02200 México D.F., México \\ Madaí Granados-Neri and Luis Humberto Mendoza-Huizar* \\ Centro de Investigaciones Químicas, Universidad Autónoma del Estado de Hidalgo, CP 42184, Hidalgo, México
}

Recebido em 20/1/09; aceito em 27/5/09; publicado na web em 6/11/09

\begin{abstract}
We carried out an electrochemical study of the cobalt electrodeposition onto glassy carbon electrode from an aqueous solution containing $10^{-2} \mathrm{M}$ of $\mathrm{CoSO}_{4}+1 \mathrm{M}\left(\mathrm{NH}_{4}\right)_{2} \mathrm{SO}_{4}$ at natural $\mathrm{pH}$ 4.5. The potentiostatic study indicated a progressive 3D nucleation and growth during the deposition process. The average diffusion coefficient calculated for this system was $2.65 \times 10^{-6} \mathrm{~cm}^{2} \mathrm{~s}^{-1}$ while the $\Delta G$ for the formation of stable nucleus was $6.50 \times 10^{-20} \mathrm{~J} /$ nuclei. The scanning electron microscopy images indicated the formation of small and homogeneous nucleus onto GCE of approximately $300 \mathrm{~nm}$.
\end{abstract}

Keyword: cobalt electrodeposition; GCE; sulfate.

\section{INTRODUCTION}

Cobalt electrodeposits have attracted a great interest in view of their potential applications in scientific and technological fields related with the digital information storage. Most of the studies have been performed onto glassy carbon electrodes, ${ }^{1-12}$ and some others onto stainless steel, ${ }^{13,14}$ gold, ${ }^{15-17}$ nickel, ${ }^{18}$ copper $^{19}$ and platinum ${ }^{20}$ electrodes. Chloride solutions have been the preferred systems for studying the electrodeposition process of cobalt, $3,5-9,14,15,17,19$ rather than sulfate systems $s^{1,4,11,12,16-18,20,21}$ or citrate solutions. ${ }^{13}$

Although, the complexing property of ammonia can be used to modulate the properties of the deposited cobalt via solution speciation, the electrodeposition of cobalt from ammoniacal solutions has not received a greater attention. ${ }^{1}$ In spite of the advantages showed by ammoniacal baths, it is important to consider that the $\left(\mathrm{NH}_{4}\right)^{+}$ions in solution are biased adsorbed on the negatively charged electrode and on the deposited Co surface, competing with the $\mathrm{H}^{+}$ions and modifying the Co nucleation environment. ${ }^{21}$ Moreover, the $\left(\mathrm{NH}_{4}\right)^{+}$ions may preferentially adsorb on certain orientations, diminishing the growth rate of $\mathrm{Co}$ nucleus. ${ }^{1}$ The $\left(\mathrm{NH}_{4}\right)^{+}$ions in the electrolyte solution are also well known to form complex species with the metal ions, reducing their oxidation rate. ${ }^{1}$ On the other hand, although the anion effect is well known, only few studies have been reported considering the influence of the $\mathrm{SO}_{4}^{-2}$ anion ${ }^{1,4,11,12,16-18,20,21}$ during the Co electrodeposition. It has been reported that the sulfate anion induces a competitive adsorption effect; in addition, the sulfate ion causes a major change in the shape of a voltammetric curve, producing new peaks which appear to be caused by an adatom-induced anion coadsorption. ${ }^{22}$ Albeit, a detailed electrochemical and AFM study of Co nucleation mechanisms on glassy carbon from ammonium sulfate solutions was carried out by Grujicic et al.; an analysis of the electrocrystallization kinetic parameters at natural $\mathrm{pH} 4.5$ was not performed by them. Thus, in this work, we carried out an electrochemical study, to determine these parameters, in order to understand the Co electrodeposition process from this system.

\footnotetext{
*e-mail: hhuizar@uaeh.edu.mx
}

\section{EXPERIMENTAL}

Co electrodepositions onto GCE were carried out from aqueous solutions containing $10^{-2} \mathrm{M}$ of $\mathrm{CoSO}_{4}+1 \mathrm{M}\left(\mathrm{NH}_{4}\right)_{2} \mathrm{SO}_{4}$ at $\mathrm{pH} 4.5$ (natural $\mathrm{pH}$ ). All solutions were prepared by using analytic grade reagents with ultra pure water (Millipore-Q system) and were deoxygenated by bubbling $\mathrm{N}_{2}$ for $15 \mathrm{~min}$ before each experiment. The working electrode was a GCE tip provided by BASTM with 0.071 $\mathrm{cm}^{2}$. The exposed surface area was polished to a mirror finish with different grades of alumina down to $0.05 \mu \mathrm{m}$ and ultrasonically cleaned before the experiments. A graphite bar with an exposed area greater than the working electrode was used as counter electrode. A saturated silver electrode $(\mathrm{Ag} / \mathrm{AgCl})$ was used as the reference electrode, and all measured potentials are referred to this scale. The electrochemical experiments were carried out in a BAS potentiostat connected to a personal computer running the BAS $100 \mathrm{~W}$ software to allow the control of experiments and data acquisition. In order to verify the electrochemical behavior of the electrode in the electrodeposition bath, cyclic voltammetry was performed in the 0.600 to $-1.300 \mathrm{~V}$ potential range. The kinetic mechanism of cobalt deposit onto GCE was studied under potentiostatic conditions by means of the analysis of the experimental potentiostatic current density transients obtained with the double potential step technique. The perturbation of the potential electrode always started at $0.600 \mathrm{~V}$. The first potential step was imposed at different potentials detailed in this work. The second step always ended at $0.600 \mathrm{~V}$. The microstructures of electrodeposits were examined by using a scanning electron microscope (SEM; JEOL6300).

\section{RESULTS AND DISCUSSION}

\section{Pourbaix diagrams}

The chemical composition of the plating bath plays a very important role during the electrodeposition process. Specific chemical species in the deposition bath can induce changes in the thermodynamic and the kinetic parameters during the electrodeposition process, since it can even modify the electronic structure of the substrate. Therefore, in order to establish the chemical species in the deposition bath and the equilibrium potentials under our experimental condi- 
tions, we have carried out a thermodynamic study by employing the Multicomponent Pourbaix Diagrams. ${ }^{23}$ The equilibrium constants of the different chemical processes associated to these species were obtained from literature. ${ }^{24}$ The speciation of $\mathrm{Co}$ in ammonia solution was examined by constructing the distribution-pH diagrams. The results are shown in Figure 1a. One may observe that under our experimental conditions the predominant specie is a cobalt sulfate pentaquo complex $\left[\mathrm{Co}\left(\mathrm{SO}_{4}\right)\left(\mathrm{H}_{2} \mathrm{O}\right)_{5}\right]$. Additionally the ratio $\left[\mathrm{Co}\left(\mathrm{SO}_{4}\right)\right.$ $\left.\left(\mathrm{H}_{2} \mathrm{O}\right)_{5}\right] /\left[\mathrm{Co}\left(\mathrm{H}_{2} \mathrm{O}\right)_{6}\right]^{2+}$ was approximately $99.2 \%$ suggesting that the electrodeposition process is carried out predominantly from $\left[\mathrm{Co}\left(\mathrm{SO}_{4}\right)\right.$ $\left(\mathrm{H}_{2} \mathrm{O}\right)_{5}$ ]. From the Figure, it is possible to note that the equilibrium potential for the $\left[\mathrm{Co}\left(\mathrm{SO}_{4}\right)\left(\mathrm{H}_{2} \mathrm{O}\right)_{5}\right] / \mathrm{Co}^{0}$ couple is $-0.353 \mathrm{~V}$ vs NHE. Thus, it is possible to suggest that in our experimental conditions the reduction process of Co follow the next two steps:

$$
\begin{aligned}
& {\left[\mathrm{Co}\left(\mathrm{SO}_{4}\right)\left(\mathrm{H}_{2} \mathrm{O}\right)_{5}\right] \rightarrow\left[\mathrm{Co}\left(\mathrm{H}_{2} \mathrm{O}\right)_{5}\right]^{2+}+\mathrm{SO}_{4}^{-2}} \\
& {\left[\mathrm{Co}\left(\mathrm{H}_{2} \mathrm{O}\right)_{5}\right]^{2+}+2 \mathrm{e} \rightarrow \mathrm{Co}^{0}+5 \mathrm{H}_{2} \mathrm{O}}
\end{aligned}
$$

Here, it is very important to mention that Grujicic et al., ${ }^{1}$ have analyzed a similar bath $10^{-2} \mathrm{M}$ of $\mathrm{CoSO}_{4}+1 \mathrm{M}\left(\mathrm{NH}_{4}\right)_{2} \mathrm{SO}_{4}$ but at $\mathrm{pH}$ 6.0. At present work we analyze a solution with the same composition but at natural $\mathrm{pH} 4.5$. Although this small difference in our solution, apparently does not bring any innovation, it is very important to comment that in our experimental conditions the hydrogen concentration is 30 times bigger than the considered previously in the literature. ${ }^{1}$ Another important change is observed in the Pourbaix's diagrams. Grujicic et al. ${ }^{1}$ indicate that in their experimental conditions the complex $\left[\mathrm{Co}\left(\mathrm{H}_{2} \mathrm{O}\right)_{6}\right]^{2+}$ is the predominant specie. In our experimental conditions, the Pourbaix's diagrams suggest that in the $\mathrm{pH}$ range $0-7.5$, two Co complex species may be obtained. From our results, $\left[\mathrm{Co}\left(\mathrm{H}_{2} \mathrm{O}\right)_{6}\right]^{2+}$ predominates in the $\mathrm{pH}$ range $0-0.7$ and $\left[\mathrm{Co}\left(\mathrm{SO}_{4}\right)\left(\mathrm{H}_{2} \mathrm{O}\right)_{5}\right]$ predominates in the $\mathrm{pH}$ range $0.7-7.5$. Thus, in our experimental conditions the electrodeposition process should occur through $\left[\mathrm{Co}\left(\mathrm{SO}_{4}\right)\left(\mathrm{H}_{2} \mathrm{O}\right)_{5}\right]$ instead of $\left[\mathrm{Co}\left(\mathrm{H}_{2} \mathrm{O}\right)_{6}\right]^{2+}$. The existence of additional free electrons through the $\mathrm{SO}_{4}^{-2}$ group in $\left[\mathrm{Co}\left(\mathrm{SO}_{4}\right)\left(\mathrm{H}_{2} \mathrm{O}\right)_{5}\right]$ might favor the adsorption process of this Co complex species onto the GCE electrode.
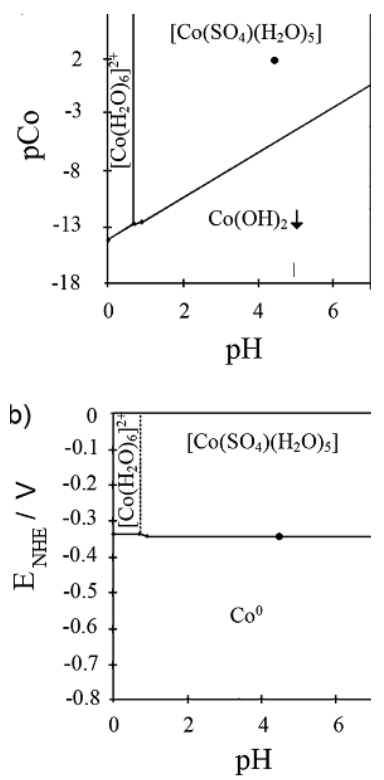

Figure 1. Pourbaix-type diagrams of the $\mathrm{Co}(\mathrm{II}) / \mathrm{Co}^{0}$ systems, a) $\mathrm{pCo}(\mathrm{II})$ " $=2.0$, $\mathrm{pSO}_{4}{ }^{\prime}=0.0$ and b) $\mathrm{pCo}(\mathrm{II}){ }^{\prime \prime}=2.0, \mathrm{pSO}_{4}{ }^{\prime}=0.0, \mathrm{pNH}_{3}{ }^{\prime}=-0.3$. The black point in the Figure represents our experimental conditions

\section{Cyclic voltammetry}

Figure 2 shows the voltammetric response, at the scan rate of 5 $\mathrm{mVs}^{-1}$, obtained from GCE $/ 10^{-2} \mathrm{M}$ of $\mathrm{CoSO}_{4}+1 \mathrm{M}\left(\mathrm{NH}_{4}\right)_{2} \mathrm{SO}_{4}$ system. It is possible to note that, at direct scan, there is the formation of a peak A at $-1.165 \mathrm{~V}$. During the inverse of the potential scan, it is possible to observe two crossovers, $\mathrm{E}_{\mathrm{C}}$ and CEP. The crossover $\mathrm{E}_{\mathrm{C}}$ is typical of the formation of a new phase involving a nucleation process and it is associated with an electrocatalytic point. ${ }^{25}$ In some cases, the second crossoverpotential CEP may be associated to the thermodynamical potential of $\mathrm{M}^{\mathrm{n}+} / \mathrm{M}$, only when CEP is independent of the switch potential $\mathrm{E}_{\lambda}$ (and only when $\mathrm{E}_{\lambda}$ is less negative of the corresponding peak potential). ${ }^{23}$ However, this was not the case for the CEP analyzed in this work. In the anodic zone, it was possible to observe two principal peaks B and $\mathrm{C}$ at around -0.497 and $-0.351 \mathrm{~V}$, respectively. Peak B may be associated to the dissolution of hydrogen rich cobalt phase. ${ }^{7}$ It is also shown that the Co electrodeposition process starts at approximately $-1.050 \mathrm{~V}\left(\mathrm{E}_{\mathrm{p}}\right)$.

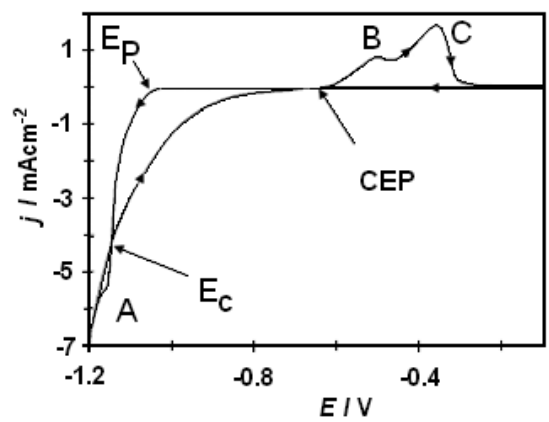

Figure 2. A typical cyclic voltammogram obtained from the GCE/10-2 $\mathrm{M}$ of $\mathrm{CoSO}_{4}+1 \mathrm{M} \mathrm{NH}_{4} \mathrm{SO}_{4}(\mathrm{pH} 4.5)$ system. The potential scan rate was started at $0.600 \mathrm{~V}$ toward the negative direction with a potential scan rate of $5 \mathrm{mVs}^{-1}$

\section{Chronoamperometric study}

Formation of new phases generally occurs through nucleation and growth mechanisms and the corresponding current transients can provide valuable information about the kinetics of electrodeposition. Figure 3 shows a set of current density transients recorded at different potentials by a double pulse potential technique. These transients were obtained by applying an initial potential of $0.600 \mathrm{~V}$ on the surface of the GCE electrode. At this potential value, the Co deposition had not still begun. After the application of this initial potential, a step of negative potential was varied on the surface of the electrode from -1.10 to $-1.20 \mathrm{~V}$, Figure 3 . This potential range was obtained from the cyclic voltammetric study in where the electrodeposition process starts at $-1.050 \mathrm{~V}$ approximately. However, the initial potential was selected as $-1.100 \mathrm{~V}$ because transients with a current maximum were clearly detected at this potential value allowing a better analysis of the kinetic parameters involved. A major influence of the hydrogen reduction process is expected when the potential applied is more negative. However a correct separation of the different contributions employing nucleation models may allow quantifying the influence of the different processes involved. All transients obtained during the reduction process, exhibited a falling current at shorter times. After this falling current, in each case, the transients showed a typical current maximum $\left(j_{m}\right)$, related to the coalescence of diffusion fields with spherical symmetry. Once the current maximum has been reached, a decay of the current was obtained, which approaches to the corresponding planar diffusion. Apparently, the general shape of these transients is very similar to those reported for a three dimensional 
nucleation process with diffusion control (3D-dc) of growing hemispherical nucleus. ${ }^{26,27}$ A classification of the nucleation as instantaneous or progressive from transients showed in Figure 3, is possible by following the criteria established by Sharifker et al. ${ }^{26}$ in where the experimental transients in a nondimensional form by plotting $j^{2} / j_{\mathrm{m}}{ }^{2} \mathrm{vs}$ $t / t_{\mathrm{m}}$ are compared with those theoretically generated from Equations 3 and 4 for instantaneous and progressive nucleation, respectively.

$$
\begin{aligned}
& \frac{j^{2}}{j_{m}^{2}}=1.9254\left(\frac{t}{t_{m}}\right)^{-1}\left\{1-\exp \left[-1.2564\left(\frac{t}{t_{m}}\right)\right]\right\}^{2} \\
& \frac{j^{2}}{j_{m}^{2}}=1.2254\left(\frac{t}{t_{m}}\right)^{-1}\left\{1-\exp \left[-2.3367\left(\frac{t}{t_{m}}\right)^{2}\right]\right\}^{2}
\end{aligned}
$$

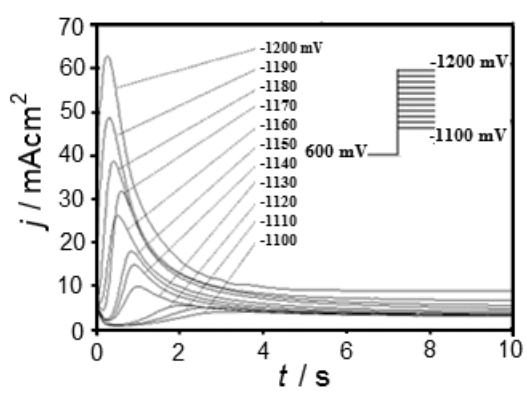

Figure 3. A set of transients obtained from $\mathrm{GCE} / 10^{-2} \mathrm{M}$ of $\mathrm{CoSO}_{4}+1 \mathrm{M}$ $\mathrm{NH}_{4} \mathrm{SO}_{4}(\mathrm{pH} 4.5)$ system by means of the double potential step technique for different potential step values $(\mathrm{mV})$ indicated in the figure. In all the cases the initial potential was $0.600 \mathrm{~V}$

Figure 4 shows the comparison of the theoretical dimensionless transients, generated by Equations 3 and 4 with experimental dimensionless current transients reported in Figure 3. It is interesting to observe that at $\left(t / t_{\mathrm{m}}<1\right)$ all transients showed a similar behavior to a progressive nucleation. At $\left(t / t_{\mathrm{m}}>1\right)$ there is a deviation from the predicted by Equations 3 and 4. This behavior may be indicative of the presence of other contributions to the overall current during the Co deposition process additional to the $3 \mathrm{D}$ nucleation contribution. ${ }^{28}$

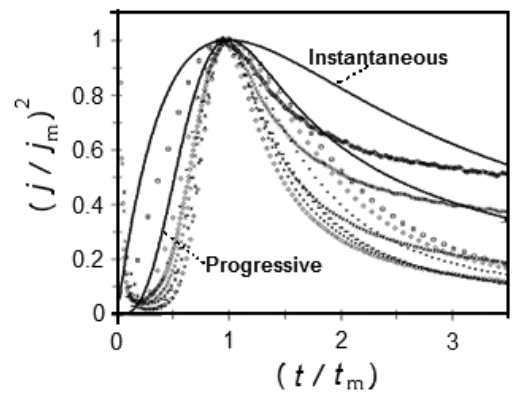

Figure 4. Comparison of different experimental transients normalized through the coordinates of its respective local maximum $\left(t_{m}, j_{m}\right)$, with the theoretical non-dimensional curves corresponding to $3 D$ instantaneous nucleation (Equation 3) and 3D progressive nucleation (Equation 4)

\section{Analysis of the transients from $\mathrm{CoSO}_{4}+\left(\mathrm{NH}_{4}\right)_{2} \mathrm{SO}_{4}$ system}

From the voltammetric study it was evidenced that the proton reduction process is present due to the existence of a hydrogen rich Co phase. Palomar-Pardavé et al. ${ }^{29}$ have proposed that when the proton reduction occurs simultaneously with the diffusion-limited 3D growth of Co centers, the overall current density is given by:
$j(t)=\left\{P_{1}+\left(P_{2} t^{(-1 / 2)}\right)\left(\frac{\phi}{\theta}\right)\right\}\{1-\exp (-b t \theta)\}$

where

$$
\begin{aligned}
& P_{1}=\left(z_{P R} F k_{P R}\right)\left(\frac{2 c M}{\pi \rho}\right)^{1 / 2} \\
& P_{2}=\frac{2 F D^{1 / 2} c}{\pi^{1 / 2}} \\
& b=(2 \pi)^{3 / 2} D\left(\frac{M c_{0}}{\rho}\right)^{1 / 2} N_{0} \\
& k_{P R}=k_{P R}^{0} \exp \left(-\frac{\alpha_{P R} z F E}{R T}\right)
\end{aligned}
$$

where $z_{P R} F$ is the molar charge transferred during the proton reduction process, $k_{P R}$ the rate constant of the proton reduction reaction, $\theta=1-(1-\exp (-A t)) / A t, \phi=1-e^{-A t} /(A t)^{1 / 2} \int_{0}^{(A t)^{\prime / 2}} e^{\lambda^{2}} d \lambda$ and all others parameters have their conventional meanings. Figure 5 shows a typical comparison of the reduction experimental current transients, with the theoretically generated by non-linear fitting of experimental data to Equation 5. It can be observed, that the model expressed by this equation adequately accounted for the behavior of experimental transient. The physical parameters obtained from the adjustments of Equation 5 were obtained (Table 1). The average diffusion coefficient calculated from the fittings was $2.65 \times 10^{-6} \mathrm{~cm}^{2} \mathrm{~s}^{-1}$. On the other hand, it is seen (Table 1) that an increment of the $k_{\mathrm{PR}}, A$ and $N_{0}$ is obtained when the overpotential applied is increased. It is interesting to observe that an increase in $k_{\mathrm{PR}}$ values indicates that the reduction proton process is favored, suggesting a competition for the active sites on the surface by $\mathrm{H}^{+}$ ions with the Co cations.

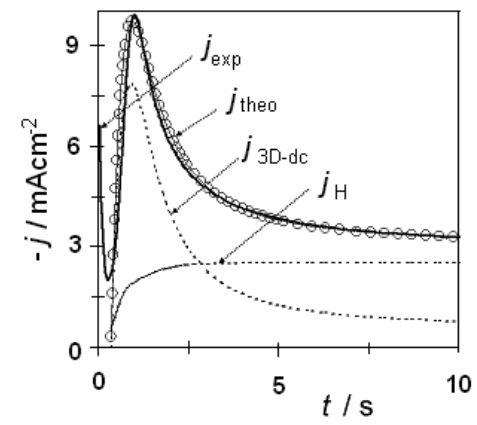

Figure 5. Comparison between an experimental current density transient ( I I ) recorded during Co electrodeposition onto a GCE electrode when a potential value of $-1.100 \mathrm{~V}$ was applied with the theoretical transient $(O)$ generated by non-linear fitting of Eq. (5) to the experimental data. In this figure are depicted the different individual contributions

\section{Analysis of the kinetic parameters}

From the nucleation rate values reported (Table 1), it is possible to calculate the Gibbs free energy of nucleation employing the next equation: ${ }^{30-32}$

$A=k_{3} \exp \left(-\frac{\Delta G}{K_{B} T}\right)=k_{3} \exp \left(-\frac{k_{4}}{\eta^{2}}\right)$

where $\Delta G$ is the Gibbs free energy of nucleation, $\mathrm{J} /$ nuclei; $K_{B}$ is the

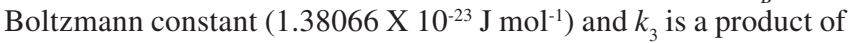


Table 1. Potential dependence for the nucleation parameters during Co electrodeposition onto a GCE electrode from aqueous solution containing $10^{-2} \mathrm{M}$ of $\mathrm{CoSO}_{4}+1 \mathrm{M}\left(\mathrm{NH}_{4}\right)_{2} \mathrm{SO}_{4}$. at $\mathrm{pH} 4.5$. The values were obtained from best-fit parameters found through the fitting process of the experimental $j-t$ plots by using Equation 5

\begin{tabular}{lccc}
\hline $\mathrm{E} / \mathrm{V}$ & $k_{\mathrm{PR}} \mathrm{X} 10^{3} / \mathrm{cm}^{2} \mathrm{~s}^{-1}$ & $A / \mathrm{s}^{-1} \mathrm{~cm}^{-2}$ & $N_{0} \mathrm{X} 10^{-6} / \mathrm{cm}^{2}$ \\
\hline-1.100 & 0.571 & 0.018 & 0.785 \\
-1.110 & 0.575 & 0.018 & 1.141 \\
-1.120 & 0.591 & 0.021 & 1.647 \\
-1.130 & 0.597 & 0.047 & 2.849 \\
-1.140 & 0.599 & 0.051 & 3.284 \\
-1.150 & 0.631 & 0.053 & 3.307 \\
-1.160 & 0.634 & 0.064 & 2.619 \\
-1.170 & 0.662 & 0.077 & 3.077 \\
-1.180 & 0.672 & 0.129 & 3.387 \\
-1.190 & 0.696 & 0.229 & 3.654 \\
-1.200 & 0.721 & 0.270 & 4.149 \\
\hline
\end{tabular}

the frequency of attachment of single atoms to the critical nucleus and the non-equilibrium Zeldovich factor and depends exponentially on the overpotential, ${ }^{33}$ and $k_{4}$ is a constant. In order to calculate the value of Gibbs free energy of nucleation from experimental transients, a $\ln A$ vs. $\eta^{-2}$ plot can be constructed according to Equation 10 , and then from the slope $k_{4}$ of the observed linear relationship, $\Delta G$ could be calculated at each particular overpotential by using the next equation:

$\left(-\frac{\Delta G}{K_{B} T}\right)=\frac{k_{5}}{\eta^{2}}$

where $T$ is the absolute temperature, $\mathrm{K}$. The plot $\ln A v s \eta^{-2}$ plot, showed a linear relationship giving a slope of -20.8 ; the $\Delta G$ calculated for this system was $6.50 \times 10^{-20} \mathrm{~J} /$ nuclei. This energy corresponds to the $\Delta G$ value requirements for the formation of stable nucleus. ${ }^{31,32}$ The $\Delta G$ value obtained is slightly bigger than the value obtained for the electrocrystallization of Co on GCE and HOPG from sodium sulfate solutions. ${ }^{12}$

Through the physical constants reported (Table 1), it was also possible to calculate the saturation number of nuclei $\left(N_{s}\right)$. This estimation was made employing Equation $12:^{34}$

$N_{S}=\left(\frac{A N_{0}}{2 k^{\prime} D}\right)^{1 / 2}$

where

$k^{\prime}=\left(\frac{8 \pi C_{o} M}{\rho}\right)^{1 / 2}$

The results obtained for $N_{\text {s }}$, are reported (Table 2). Observe that the $N_{\mathrm{s}}$ values increased with the applied potential. It is important to mention that, due to the exclusion zones of the deposit, caused by the hemispherical diffusional gradients of 3D nucleus, $N_{\mathrm{s}}$ will be always lower than $N_{0}$ values at the same applied potential, and both grow in accordance with a more negative potential. The $N_{s} / N_{0}$ ratio which can be defined as the efficiency of use of the surface available nucleation sites is reported (Table 2). Observe that the $N_{s}$ $N_{0}$ ratio is potential dependent and its value is relatively low. This result may be due to the occupation of active sites by $\left(\mathrm{NH}_{4}\right)^{+}$ions adsorbed on the surface. ${ }^{35}$
Table 2. Potential dependence of the $N$ from aqueous solution containing $10^{-2} \mathrm{M}$ of $\mathrm{CoSO}_{4}+1 \mathrm{M}\left(\mathrm{NH}_{4}\right)_{2} \mathrm{SO}_{4}$ at $\mathrm{pH} 4.5$ calculated from physical constants reported in this work (Table 1) and Equation 12

\begin{tabular}{lcl}
\hline $\mathrm{E} / \mathrm{V}$ & $N_{\mathrm{s}} \mathrm{X} 10^{-6} \mathrm{~cm}^{-2}$ & $N_{\mathrm{s}} / N_{0}$ \\
\hline-1.100 & 0.035 & 0.045 \\
-1.110 & 0.041 & 0.036 \\
-1.120 & 0.055 & 0.033 \\
-1.130 & 0.107 & 0.038 \\
-1.140 & 0.119 & 0.036 \\
-1.150 & 0.122 & 0.037 \\
-1.160 & 0.119 & 0.046 \\
-1.170 & 0.142 & 0.046 \\
-1.180 & 0.193 & 0.057 \\
-1.190 & 0.266 & 0.073 \\
-1.200 & 0.308 & 0.074 \\
\hline
\end{tabular}

In the framework of the atomistic theory of electrolytic nucleation, it is possible to estimate the critical size of the Co nucleus $(n)$ from the potential dependence of $A$ through the following Equation: ${ }^{36}$

$n_{c}=\left(\frac{k_{B} T}{z e_{0}}\right)\left(\frac{d \ln A}{d \eta}\right)-\alpha_{C o}$

where $\alpha_{C o}$ is the transfer coefficient for Co reduction. The plot ln $A$ vs $\eta$ showed a linear tendency with a $\mathrm{d}(\ln A) / \mathrm{d}(E)=27.5$. Thus, the critical cluster's size $\left(n_{c}\right)$ calculated employing eq(14) was $n=0$ suggesting that each active site is a critical nucleus on the GCE surface. Similar results have been obtained for the Co electrodeposition from sodium sulfate solutions onto GCE and HOPG electrodes. ${ }^{12}$

\section{Morphological analysis}

The morphology of the electrodeposits was studied by scanning electron microscopy (SEM). SEM micrographs of an electrodeposit formed potentiostatically at $-1.100 \mathrm{~V}$, at different magnifications, are shown in Figure 6a-c. From these images, a homogeneous Co distribution is observed onto the GCE. Also observe that the Co clusters are small and with similar size of approximately $300 \mathrm{~nm}$. In a recent work carried out by our group, the apparition of small clusters with similar size has been explained considering the influence of the $\left(\mathrm{NH}_{4}\right)^{+}$
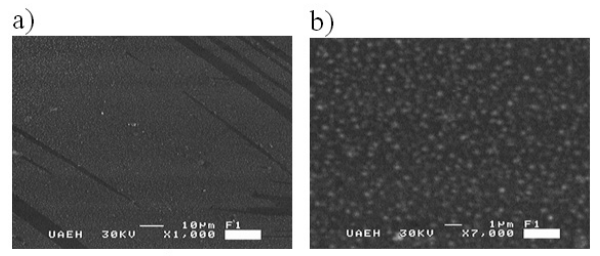

c)

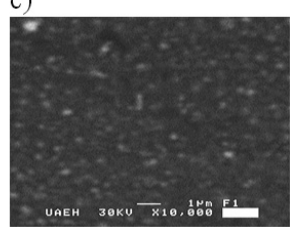

Figure 6. SEM images of Co electrodeposited under potentiostatic conditions

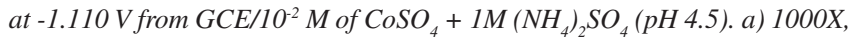
b) $7000 \mathrm{X}$ and c) $10000 \mathrm{X}$ 
adsorption process on carbon surface.$^{35}$ In that work, it has showed that the $\left(\mathrm{NH}_{4}\right)^{+}$cations are adsorbed on the electrode surface; they stop the diffusion of Co adatoms towards the growing cluster, which in turn, will induce the growth of smaller clusters between them.

\section{CONCLUSIONS}

We have studied Co electrodeposition onto glassy carbon electrode (GCE) from $10^{-2} \mathrm{M} \mathrm{CoSO}_{4}, 1 \mathrm{M}\left(\mathrm{NH}_{4}\right)_{2} \mathrm{SO}_{4}$ aqueous solution by using the cyclic voltammetric and potentiostatic techniques. From the thermodynamic study, it was possible to suggest that under our experimental conditions, the predominant chemical species was the $\left[\mathrm{Co}\left(\mathrm{SO}_{4}\right)\left(\mathrm{H}_{2} \mathrm{O}\right)_{5}\right]$ complex and the equilibrium potential was -0.353 $\mathrm{V}$ vs NHE. Nucleation parameters such as nucleation rate, density of active nucleation sites and saturation nucleus were determined from potentiostatic studies. The morphological analysis indicated the formation of small Co clusters with similar size, approximately $300 \mathrm{~nm}$, on the carbon surface.

\section{AKNOWLEDGMENTS}

M. Granados-Neri is grateful for a graduate student fellowship from CONACyT. We gratefully acknowledge financial support from CONACyT project APOY-COMPL-2008 No. 91261 and to the Universidad Autónoma del Estado de Hidalgo. Authors acknowledge C. A. Galan-Vidal for valuable help to construct the Pourbaix's diagrams and J. Hernández-Ávila for the SEM technical assistance. We are also grateful to the reviewers of the manuscript for valuable suggestions.

\section{REFERENCES}

1. Grujicic, D.; Pesic B.; Electrochim. Acta 2004, 49, 4719.

2. Gomez E.; Valles E.; J. Appl. Electrochem. 2002, 32, 693.

3. Floate, S.; Hyde, M.; Compton, R.G.; J. Electroanal. Chem. 2002, 523, 49.

4. Soto, A. B.; Arce, E. M.; Palomar-Pardave, M.; González, I.; Electrochim. Acta 1996, 41, 2647.

5. Myung, N.; Ryu, K. H.; Sumodjo, P. T. A.; Nobe, K.; Electrochemical Society Proceedings 1998, PV97, 270.

6. Palomar-Pardave, M.; González, I.; Soto, A. B.; Arce, E. M.; J. Electroanal. Chem. 1998, 443, 125.

7. Mendoza-Huizar, L. H.; Rios-Reyes, C. H.; Rivera, M.; Galán-Vidal, C. A.; Advances in Technology of Materials and Materials Processing 2006, 8, 152 .

8. Correia, A. N.; de Oliveira, R. C. B.; Lima-Neto, P.; J. Braz. Chem. Soc. 2006, 17, 1, 90.

9. Gu, M.; Yang, F. Z.; Huang, L.; Yao, S. B.; Zhou, S. M.; Chin. Chem. Lett. 2004, 15, 981.
10. Mishra, K.G.; Singh, P.; Muir, D.; J. Appl. Electrochem. 2002, 32, 1391.

11. Fletcher, S.; Halliday, C. S.; Gates, D.; Westcott, L. T.; Nelson, G.; J. Electroanal Chem. 1983, 159, 267.

12. Rios-Reyes, C. H.; Mendoza-Huizar, L. H.; Rivera, M.; J. Solid State Electrochem. 2009, in press. DOI 10.1007/s10008-009-0816-3.

13. Abd El Rehim, S. S.; Abd El Wahaab, S. M.; Ibrahim, M. A. M.; Dankeria, M. A.; J. Chem. Technol. Biotechnol. 1998, 73, 369.

14. Tutunaru, B.; Patru, A.; Preda, M.; Rev. Chim. (Bucharest, Rom.), 2006, $57,598$.

15. Mendoza-Huizar, L. H.; Robles, J.; Palomar-Pardavé, M.; J. Electroanal. Chem. 2002, 521, 95.

16. Mendoza-Huizar, L. H.; Robles, J.; Palomar-Pardavé, M.; J. Electroanal. Chem. 2003, 545, 39.

17. Kabulska, F.; J. Appl. Electrochem. 2006, 36, 131.

18. Cui, C. Q.; Jiang, S. P.; Tseung, A. C. C.; J. Electrochem. Soc. 1990, 137, 3418.

19. Bhuiyan, M. S.; Taylor, B. J.; Paranthaman, M.; Thompson, J. R.; Sinclair, J. W.; J. Mater. Sci. 2008, 43, 1644.

20. Bento, F. R.; Mascaro, L. H.; J. Braz. Chem. Soc. 2002, 13, 502.

21. Bao, Z. L.; Kavanaugh, K. L.; J. Cryst. Growth. 2006, 287, 514.

22. Wheeler, R.; Wang, J. X.; Adzic, R. R.; J. Electroanal. Chem. 1995, 387, 115.

23. Rojas-Hernández, A.; Ramírez, T. M.; Ibáñez, J. G.; González, I.; J. Electrochem. Soc. 1991, 138, 365.

24. Academic Software, The IUPAC Stability Constants Database, 1992 2000.

25. Greef, R.; Peat, R.; Peter, L. M.; Pletcher, D.; Robinson, J.; Instrumental Methods in Electrochemistry, Ellis Horwood; Chichester, 1985, ch. 9.

26. Scharifker, B.; Hills, G.; Electrochim. Acta 1983, $28,879$.

27. Scharifker, B. R.; Mostany, J.; J. Electroanal. Chem. 1984, 177, 13.

28. Mendoza-Huizar, L. H.; Robles, J.; Palomar-Pardavé, M.; J. Electroanal. Chem. 2003, 545, 39.

29. Palomar-Pardavé, M.; Scharifker, B. R.; Arce, E. M.; Romero-Romo, M.; Electrochim. Acta 2005, 50, 4736.

30. Southampton Electrochemistry Group; Instrumental Methods in Electrochemistry, Wiley: New York, 1985, p. 923.

31. Mostany, J.; Mozota, J.; Scharifker, B. R.; J. Electroanal. Chem. 1984, $177,25$.

32. Serruya, A.; Mostany, J.; Scharifker, B. R.; J. Electroanal. Chem. 1999, 464, 39.

33. Milchev, A.; Electrocrystallization: Fundamentals of nucleation and growth, Kluwer Academic Publishers, 2002, Chapter 2.2.3.

34. Scharifker, B. R.; Acta Científica Venezolana 1984, 35, 211.

35. Rivera, M.; Rios-Reyes, C. H.; Mendoza-Huizar, L. H.; Appl. Surf. Sci. 2008, 255, 1754.

36. Milchev, A.; Contemporary Physics 1991, 32, 321. 